\title{
Article \\ Using Machine Learning to Identify the Potential Marginal Land Suitable for Giant Silvergrass (Miscanthus $\times$ giganteus)
}

\author{
Mengmeng Hao ${ }^{1,2,+}$, Shuai Chen ${ }^{1,2,+}\left(\mathbb{D}\right.$, Yushu Qian ${ }^{1}$, Dong Jiang ${ }^{1,2,3, * \mathbb{C}}$ and Fangyu Ding ${ }^{1,2, *}$ \\ 1 Institute of Geographic Sciences and Natural Resources Research, Chinese Academy of Sciences, \\ 11A Datun Road, Chaoyang District, Beijing 100101, China; haomm@igsnrr.ac.cn (M.H.); \\ chenshuai17@mails.ucas.ac.cn (S.C.); qianyushu@igsnrr.ac.cn (Y.Q.) \\ 2 College of Resources and Environment, University of Chinese Academy of Sciences, Beijing 100049, China \\ 3 Key Laboratory of Carrying Capacity Assessment for Resource and Environment, \\ Ministry of Land \& Resources, Beijing 100101, China \\ * Correspondence: jiangd@igsnrr.ac.cn (D.J.); dingfy@igsnrr.ac.cn (F.D.) \\ + These authors contributed equally to this work.
}

Citation: Hao, M.; Chen, S.; Qian, Y.; Jiang, D.; Ding, F. Using Machine Learning to Identify the Potential Marginal Land Suitable for Giant Silvergrass (Miscanthus $\times$ giganteus). Energies 2022, 15, 591. https:// doi.org/10.3390/en15020591

Academic Editors: Luigi Pari and Mariusz J. Stolarski

Received: 23 November 2021

Accepted: 7 January 2022

Published: 14 January 2022

Publisher's Note: MDPI stays neutral with regard to jurisdictional claims in published maps and institutional affiliations.

Copyright: (C) 2022 by the authors. Licensee MDPI, Basel, Switzerland. This article is an open access article distributed under the terms and conditions of the Creative Commons Attribution (CC BY) license (https:// creativecommons.org/licenses/by/ $4.0 /)$.

\begin{abstract}
Developing biomass energy, seen as the most important renewable energy, is becoming a prospective solution in attempting to deal with the world's sustainability-related challenges, such as climate change, energy crisis, and carbon emission reduction. As one of the most promising second-generation energy crops, giant silvergrass (Miscanthus $\times$ giganteus) is highly valued for its high potential for biomass production and low maintenance requirements. Mapping the potential global distribution of marginal land suitable for giant silvergrass is an essential prerequisite for the development of giant silvergrass-based biomass energy. In this study, a boosting regression tree was used to identify the marginal land resources for giant silvergrass cultivation using influencing factors, which include climate conditions, soil conditions, topography conditions, and land use. The results indicate that there are 3068.25 million hectares of land resources worldwide suitable for giant silvergrass cultivation, which are mainly located in Africa (902.05 million hectares), Asia (620.32 million hectares), South America (547.60 million hectares), and North America (529.26 million hectares). Among them, countries with the most land resources, Russia and Brazil, have the firstand second-highest amounts of suitable marginal land for giant silvergrass, with areas of 373.35 and 332.37 million hectares, respectively. Our results also rank the involved factors by their contribution. Climatic conditions have the greatest influence on the spatial distribution of giant silvergrass, with an average contribution of $74.38 \%$, followed by land use, with a contribution of $17.38 \%$. The contribution of the soil conditions is $7.26 \%$. The results of this study provide instructive support for future biomass energy policy development.
\end{abstract}

Keywords: giant silvergrass; boosting regression tree; marginal land; environmental suitability

\section{Introduction}

Climate change is a global issue that will severely threaten human security without proper response to it [1]. In recent decades, many international organizations have set up policies to cope with climate change. The Paris Agreement of the 21st United Nations Climate Change Conference (COP21) set a goal of guaranteeing global average temperature increases below $2{ }^{\circ} \mathrm{C}$ above pre-industrial levels and, if possible, putting further efforts to limit the temperature increase to $1.5^{\circ} \mathrm{C}$ [2]. At COP26, it was proposed that all signatories should resolutely pursue the ultimate goal of $1.5^{\circ} \mathrm{C}$ [3-5]. Emissions of greenhouse gases must be reduced if we want to avoid further global warming [6]. Up until now, a great deal of effort has been put into mitigating global warming, and developing renewable resources turns out to be one of the most effective means that is conducive to carbon emission reduction $[7,8]$. As one of the reliable and renewable energy sources, bioenergy occupies 
an important position in the energy system because of its extensive sources and pollutionreducing capability $[9,10]$. According to the Renewables 2021 Global Status Report, modern bioenergy provided 5.1\% of total global final energy required in 2019, accounting for around half of all renewable energy in final energy consumption [11]. Among all the plants producing bioenergy, giant silvergrass (Miscanthus $\times$ giganteus), a tall C4 perennial rhizomatous grass from Asia, is the most popular energy crop of the genus Miscanthus due to its physiological characteristics [12,13]. It can survive in a wide range of climatic conditions, with temperatures $\geq-23^{\circ} \mathrm{C}$ and precipitation $\geq 400 \mathrm{~mm}[13,14]$. In addition, it contains high quantities of carbohydrates, including approximately $45.5 \%$ cellulose, 29.2\% hemicellulose, and 23.8\% lignin (dry weight, $w / w$ ) [15].

To assess the biomass production of energy plants, we need to start by understanding their potential spatial distribution. In addition, it is our assumption that the grass will only be planted on the widely available marginal land in case its exploitation takes up land for food production, incurring more environmental consequences $[16,17]$. Currently, there are two main methods to identify the marginal land suitable for energy plants. One is a multi-factor analysis method, which distinguishes the marginal land by comprehensively considering the crops' growing conditions. Zhuang et al. used this method to identify marginal land for bioenergy development in China, aided by the data of several major energy plants on the eco-environmental requirements and natural habits [18]. Taking into account the growing conditions of each energy plant, they were able to map the marginal land resource distribution of cassava [19], switchgrass [20], Pistacia chinensis [21], and Jatropha curcas L. in China [22]. In another case, Liu et al. used the Geographic Information System (GIS) software combined with land use datasets to identify the potential marginal land area in Canada through multi-factor analysis [23]. The other method, machine learning, has been introduced by some scholars for land resource identification, with increasing attention paid to big data and machine learning technology [24,25]. Yang et al. performed land productivity estimation in the contiguous United States through machine learning based on biophysical properties, including climate, soil, and land slope [26]. Jiang et al. mapped the global marginal land suitable for Sorghum bicolor (L.) Moench [27], switchgrass [28], and cassava [29] from the perspective of environmental suitability using the machine learning method along with the plants' occurrence records. Compared to the multi-factor analysis method, the machine learning method could identify the environmental niche of giant silvergrass and provide the relative importance of factors, making a reasonable assessment to support the long-term planning of giant silvergrass-based bioenergy resources [29].

So far, we have found no attempt to map the potential marginal land suitable for growing giant silvergrass globally. Therefore, the goal of this study was to (1) identity the global marginal land resources for giant silvergrass with a machine learning method, and (2) evaluate the contribution of each involved environmental factor to the worldwide spatial distribution of giant silvergrass.

\section{Materials and Methods}

\section{Step 1: The preparation of the occurrence records and pseudo-absence records}

The technical flow chart shown in Figure 1 illustrates the research procedures of this study, which can be boiled down to 3 steps. The first step was to generate the occurrence records and pseudo-absence records of giant silvergrass to meet the requirement of the model training process. We gained access to the occurrence records of Miscanthus on the Global Biodiversity Information Facility website (https: / www.gbif-uat.org/ (accessed on 2 October 2021)), which provides the global samples of known giant silvergrass cultivation, including 2000 georeferenced records. To obtain the raster data for the records, we used the ArcGIS software (https:/ / www.arcgis.com/index.html (accessed on 20 May 2021)) to transform the point data into raster data with $5 \times 5 \mathrm{~km}$. Since a raster may contain more than one georeferenced record, eventually we acquired a total of 1839 grid record samples. The same number of pseudo-absence records appearing in unsuitable growing regions were also required to build the simulating model. Here, we used the land cover, temperature, 
and precipitation to determine the pseudo-absence records distributed in these regions. In terms of identifying unsuitable land resources for giant silvergrass cultivation, the urban, barren, and cropland were excluded for their unavailability [20]. In addition, areas with low temperatures (temperatures $<-23{ }^{\circ} \mathrm{C}$ ) or low precipitation (precipitation $<400 \mathrm{~mm}$ ) were also deemed unsuitable for giant silvergrass [15]. Therefore, the same number of pseudo-samples were randomly drawn from these regions.

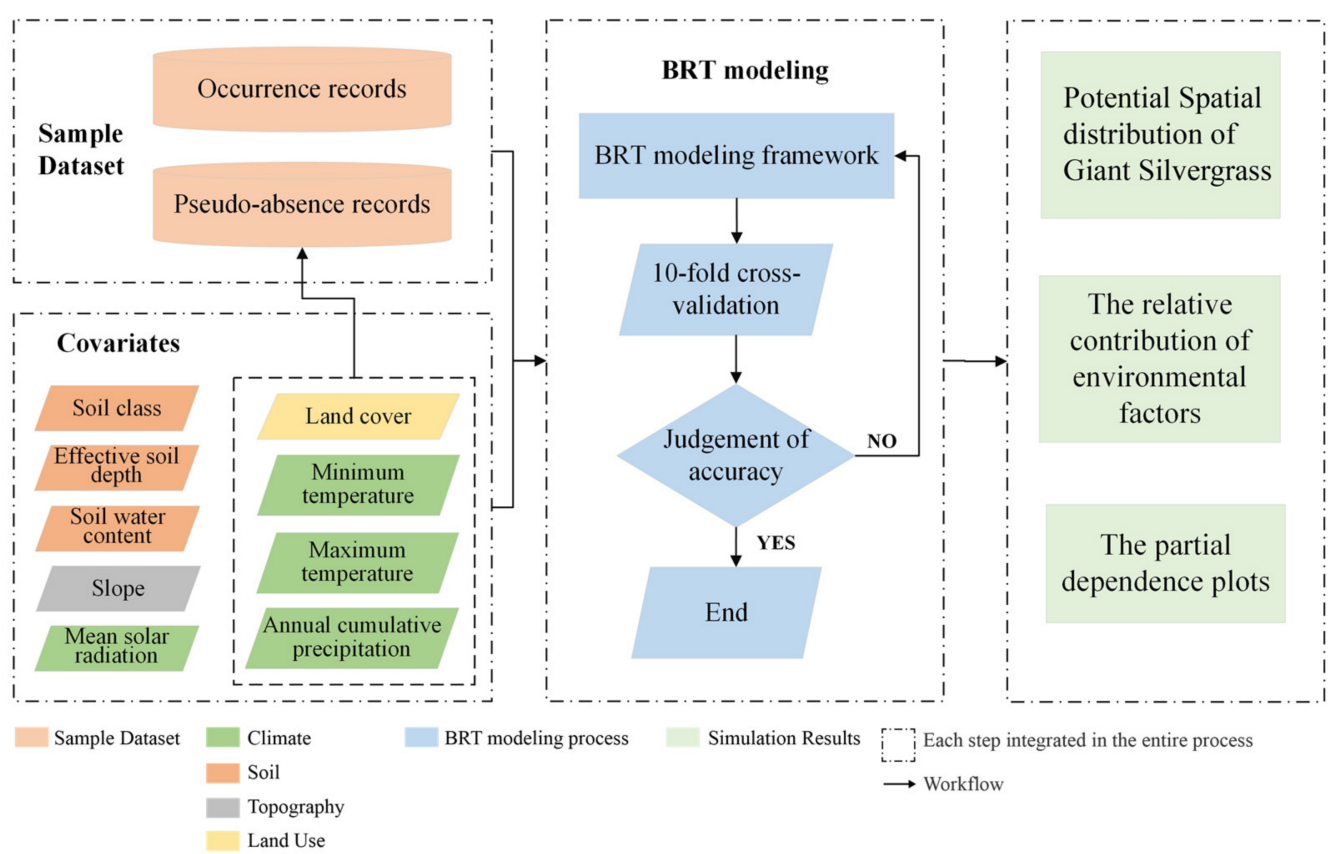

Figure 1. The technical flow chart of this study.

\section{Step 2: Constructing covariates}

In our second step, we carefully selected covariates with respect to their effects on the overall spatial distribution of giant silvergrass. It is well-known that the growth of crops depends heavily on harvest time, soil and climate conditions, and management practices [30]. Considering the growing conditions of giant silvergrass and the availability of data, we selected climate conditions, soil conditions, topography conditions, and land use as covariates of our model. We applied Geographic Information System (GIS) techniques to process all the covariates and sample data to the same spatial resolution and coordinate system. The specific environmental factors that we used as the covariates in this study are listed in Table 1. The detailed information about the covariates is available in our previous paper [28].

Table 1. The covariates in this study.

\begin{tabular}{ccc}
\hline Environmental Conditions & Covariates & Data Sources \\
\hline Climate & $\begin{array}{c}\text { Maximum temperature } \\
\text { Minimum temperature } \\
\text { Annual cumulative precipitation } \\
\text { Mean solar radiation }\end{array}$ & Adapted from WorldClim database, version 2.0 [31] \\
Soil & $\begin{array}{c}\text { Effective soil depth } \\
\text { Soil class } \\
\text { Soil water content }\end{array}$ & Adapted from consortium for spatial information [33] \\
\hline Topography & Slope & Adapted from The NASA shuttle radar topography \\
Land use & Land cover & Adapted from NASA's earth observatory group [35,36] \\
\hline
\end{tabular}




\section{Step 3: Model selection and realization}

In the final step, we needed to select a model to run the simulation of the global suitability for giant silvergrass cultivation and identify the contribution of each factor. We adopted a machine learning method, boosting regression trees (BRTs), to simulate the potential spatial distribution of giant silvergrass. The BRT model is a self-learning method based on the classification and regression tree, which can improve the stability and prediction accuracy of the model by generating multiple regression trees through random selection and self-learning methods $[37,38]$. A certain amount of sample data is randomly selected several times during the operation to analyze the influence of the independent variable on the dependent variable, while the remaining sample data are used to test the fitting results, and the averages of the generated multiple regressions are the final output $[39,40]$. The BRT method can yield the influence of the independent variable on the dependent variable and the interrelationship between that independent variable and the dependent variable when the other independent variables are taken as the mean or constant [41]. We believe it was a wise choice to select the BRT model for this study due to its success in the application of simulating species distribution and identifying marginal land for energy plants, such as sweet sorghum [28] and cassava [29].

During the model process, all 3678 grid units, including 1839 occurrence records and the same number of randomly sampled pseudo-absence records, were used as the dependent variables, while the 9 covariates were introduced as independent variables. We carried out 100 simulations to ensure our results' reliability, and we randomly selected pseudo-absence records during each simulation. The $\mathrm{R}$ version 3.3.3 statistical programming environment was used in combination with the extension packages (i.e., dismo, caret, and gbm) to build the BRT model. We set the learning rate to 0.005 , drawing $50 \%$ of the data each time for training while leaving the rest data for testing. In addition, we applied ten-fold cross-validation to verify the accuracy of the simulation.

\section{Results}

\subsection{Accuracy Evaluation}

For the simulation of globally potential land resources done with the BRT model, we assembled a database of geolocated sites where giant silvergrass occurs worldwide, containing a total of 1839 records. Visually, these globally scattered sample points are mostly located in regions predicted to have relatively high environmental suitability for giant silvergrass, shown in Figure 2.

In addition, we used both the 10-fold cross-validation and standard deviation values that quantify the uncertainty of the spatial prediction to evaluate the performance of the BRT model for simulating the potential land resources for growing giant silvergrass.

The test results using the two above techniques indicate high accuracy of the model's simulation, with the 10-fold cross-validation of AUC $=0.987 \pm 0.002$, and the low-level pixel-wise uncertainty in spatial prediction depicted in Figure 3. 


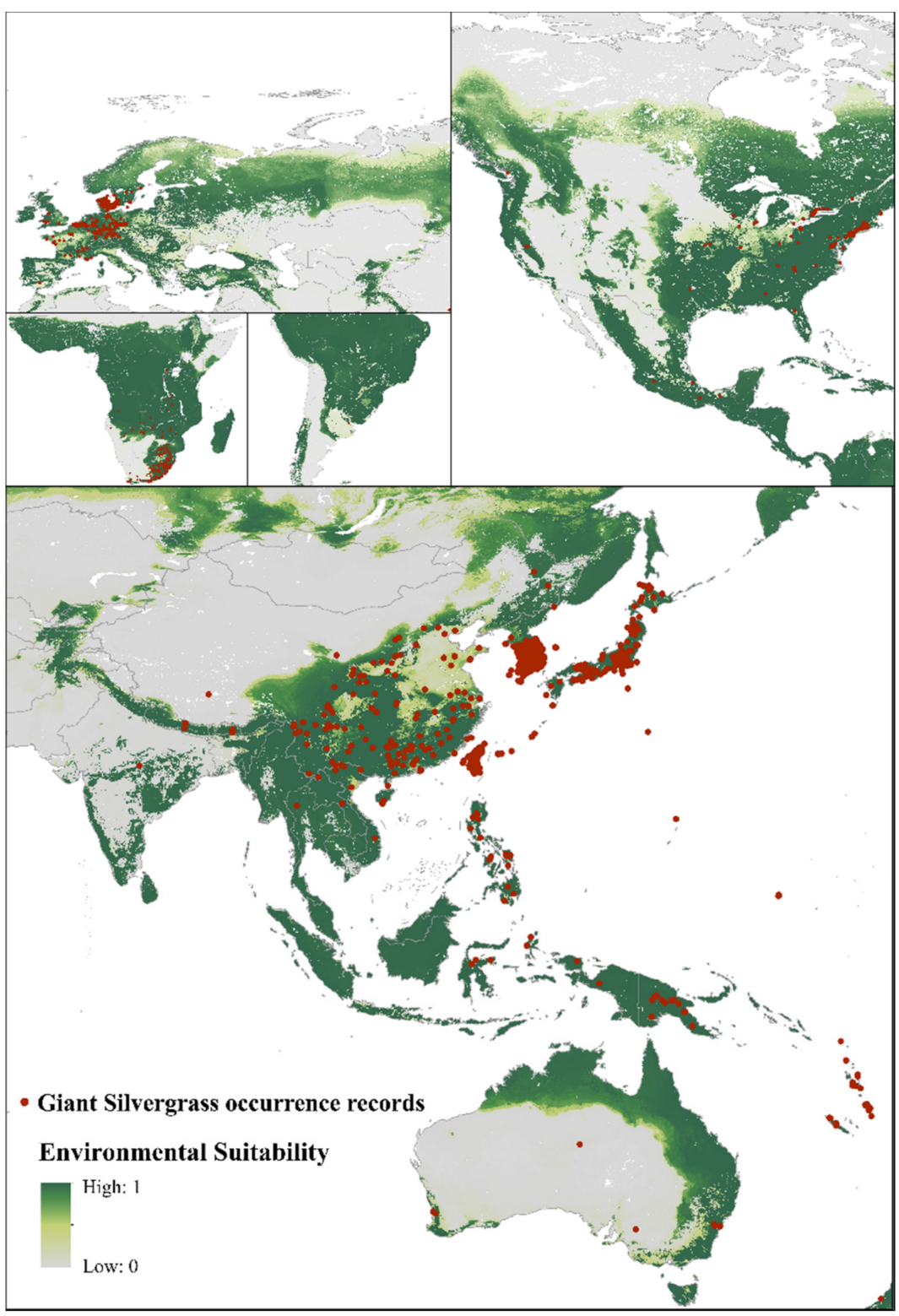

Figure 2. Spatial distribution of the global occurrence records for giant silvergrass.

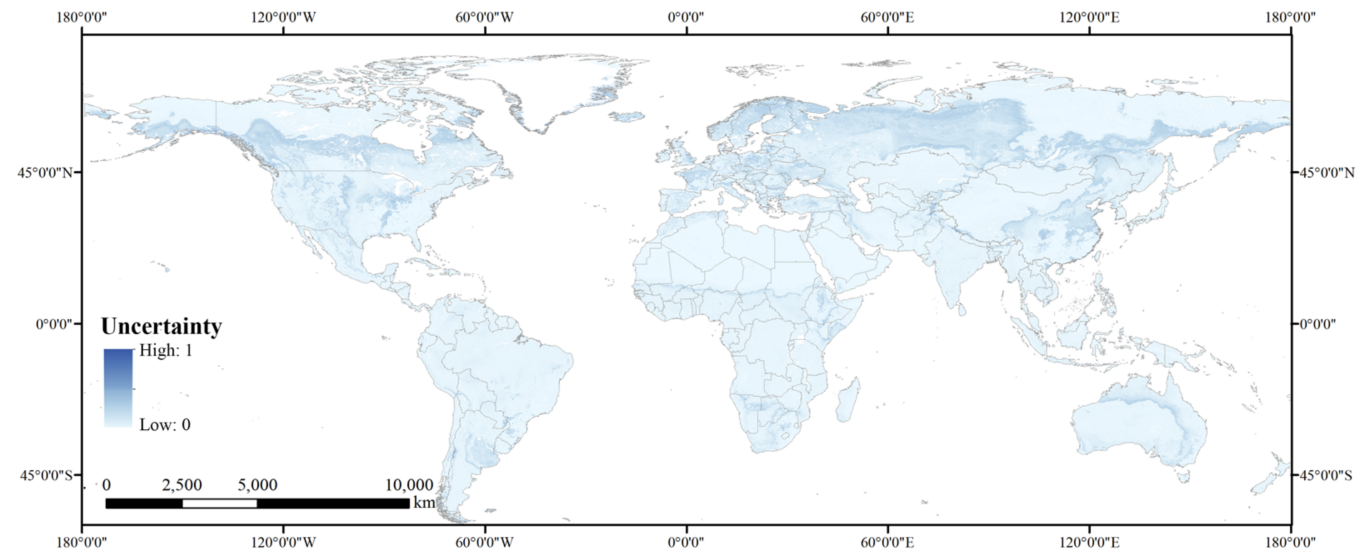

Figure 3. Visualized uncertainty in spatial prediction using standard deviation values calculated for each pixel across the model ensemble. 


\subsection{Potential Land Resources Suitable for Giant Silvergrass}

\subsubsection{Potential Environmentally Suitable Regions for Giant Silvergrass}

The global map showing the environmentally suitable land resources for giant silvergrass is presented in Figure 4. According to the map, the preferred locations for growing giant silvergrass are mainly distributed in the tropics, subtropics, and temperate regions and concentrated in Central and Southern Africa, a quite large proportion of South America and Europe, Central and Southern North America, the western part of Northern Asia and Southeast Asia, as well as most coastal regions of Oceania.

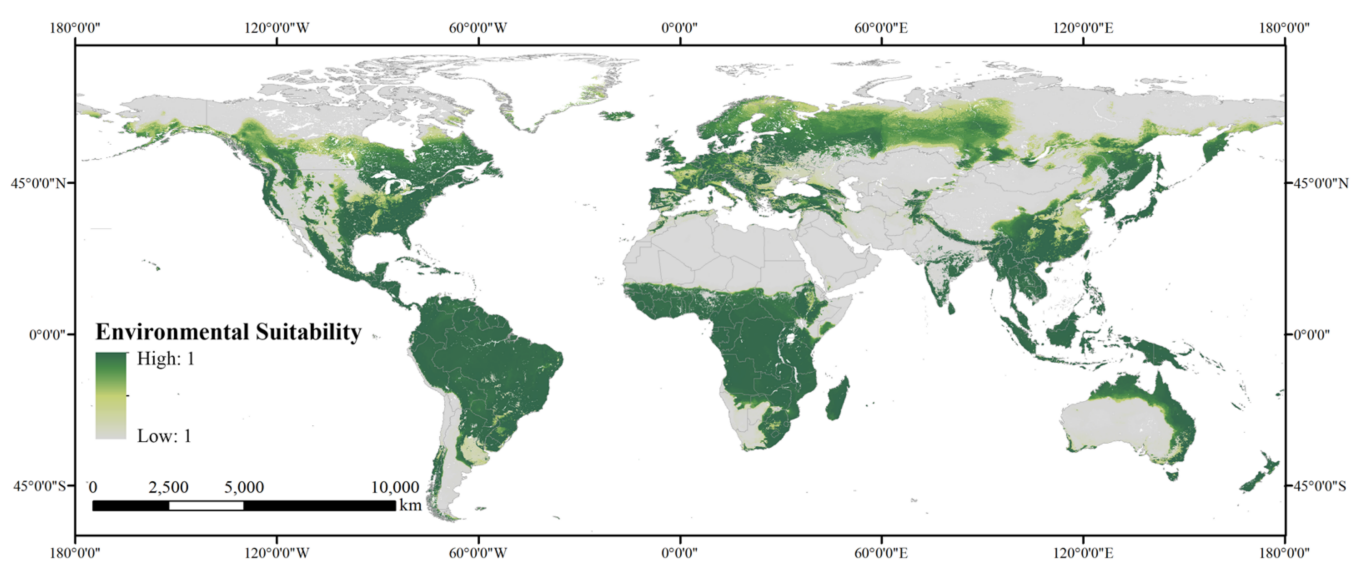

Figure 4. Global map of the predicted environmental suitability for giant silvergrass.

In Africa, areas with the highest suitability for giant silvergrass are mostly distributed in Central and Southern Africa, including Angola, Zaire, South Sudan, Tanzania, Zambia, Ethiopia, Central African Republic, and South Africa. In North America, the potential areas are mainly distributed in the Southern United States, parts of Canada (Western Canada, Ontario, Quebec, and Atlantic provinces), Venezuela, the northern and central parts of Argentina, Bolivia, and Peru. Environmentally suitable areas for giant silvergrass cover almost the whole of Europe except its southeast part located in Russia, bordering Ukraine, which is scarcely distributed with suitable areas as well. In Asia, countries in the western part of Northern Asia and Southeast Asia exhibit high suitability for giant silvergrass, including Myanmar, Laos, Thailand, Vietnam, Cambodia, Indonesia. Besides, Western and Southeast Russia, India coastal regions, as well as regions outside of North and Western China are also predicted to have a high potential for growing giant silvergrass. In Oceania, while other countries are almost wholly at the disposal of potential giant silvergrass cultivation, only the northern and eastern parts of Australia are identified as suitable areas for planting.

\subsubsection{Potential Environmentally Suitable Regions for Giant Silvergrass}

We used the threshold value of 0.5 to sift out all the qualified $5 \times 5 \mathrm{~km}$ units for identifying the qualified land resources for giant silvergrass cultivation. On this basis, we selected only shrublands, savannas, and grasslands as qualified marginal lands. The final global map of potential marginal land resources suitable for giant silvergrass is depicted in Figure 5. 


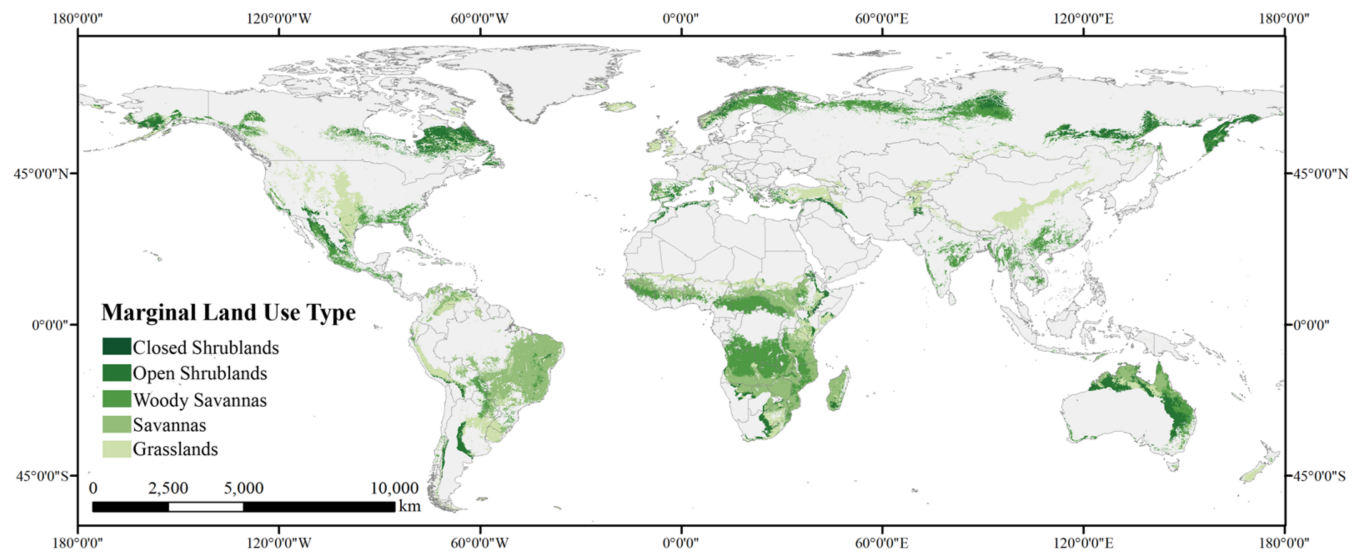

Figure 5. Global distribution of the estimated potential marginal land resources supporting giant silvergrass cultivation.

Globally, the suitable land covers a total area of 3068.25 million hectares. The results of quantified potential marginal land suited for planting giant silvergrass are listed in Table 1 in descending order by size.

Africa has more suitable marginal land resources than any other continent in the world, the area of which is 902.05 million hectares. After Africa, Asia owns the second-largest amount of suitable land for giant silvergrass, which is 620.32 million hectares, followed by South America's 547.60 million hectares and North America's 529.26 million hectares. The two remaining continents, Europe and Oceania, each have less than half the land resources of North America, with 241.88 and 227.15 million hectares, respectively.

Only six countries possess more than 100 million hectares of marginal land for potential giant silvergrass cultivation. Among them, Russia and Brazil possess the firstand second-largest amounts of suitable land, the only two countries having more than 300 million hectares of land resources with areas of 373.35 and 332.37 million hectares, respectively. The following countries are the United States (234.70 million hectares), Australia (215.96 million hectares), Canada (210.31 million hectares), and China (129.64 million hectares). The sum of suitable land in all six countries is 1496.35 million hectares, accounting for nearly half of the total area $(48.77 \%)$. Aside from the countries listed in Table 2, there are also a few countries in Africa possessing considerable amounts of suitable land, such as Angola (95.21 hectares), Zaire (79.24 hectares), and Sudan (70.19 hectares).

Table 2. Potential marginal land resources suitable for giant silvergrass in major global regions and the countries with an area of suitable land > 100 million hectares.

\begin{tabular}{ccc}
\hline & Region & Estimated Potential Area (Million Hectare) \\
\hline \multirow{4}{*}{ Continent } & Africa & 902.05 \\
& Asia & 620.32 \\
& South America & 547.60 \\
& North America & 529.26 \\
& Europe & 241.88 \\
& Oceania & 227.15 \\
\hline \multirow{3}{*}{ Country } & Russia & 373.35 \\
& Brazil & 332.37 \\
& United States & 234.70 \\
& Australia & 215.96 \\
& Canada & 210.31 \\
& China & 129.64 \\
\hline
\end{tabular}


In terms of the global land-use composition of potential land resources, $31.44 \%$ of the total is woody savannas, followed by $26.55 \%$ as savannas, $24.67 \%$ as grasslands, $17.15 \%$ as open shrublands, and only $0.19 \%$ as closed shrublands.

Regarding the land-use structure in each continent shown in Figure 6, potential land resources in Africa are mostly savannas $(41.48 \%$ ) and woody savannas $(38.12 \%)$, while the total area of grasslands and shrublands only take $20.40 \%$. In Asia, the largest proportion is taken by woody savannas (36.74\%), and the following types are grasslands (34.45\%), open shrublands $(27.28 \%)$, and savannas $(1.44 \%)$, while its close shrublands, as negligible as in other continents, only contributes $0.09 \%$ to the total area. In South America, the predominant land-use type of suitable land resources is savannas, contributing $61.39 \%$ to the total amount, followed by grasslands $(23.71 \%)$, woody savannas $(9.05 \%)$, and open shrublands (5.82\%). In North America, grasslands take $34.87 \%$ of the total suitable land while woody savannas and open shrublands contribute similarly to the whole, with a percentage of $28.76 \%$ and $28.30 \%$, respectively, leaving $7.79 \%$ as the savannas. In Europe, potential land for growing giant silvergrass mainly consists of woody savannas (56.49\%), grasslands $(28.75 \%)$, and open shrublands $(13.46 \%)$. The potential land resources in Oceania are composed of open shrublands (36.51\%), woody savannas $(23.97 \%)$, savannas $(22.47 \%)$, and grasslands $(16.89 \%)$.

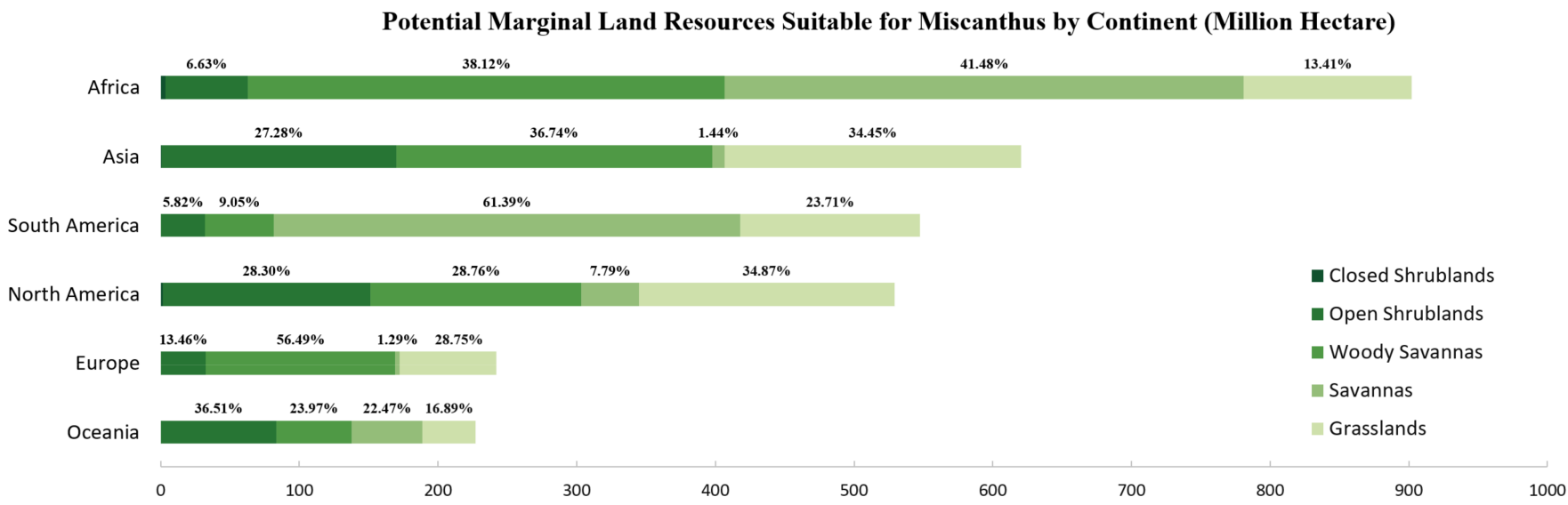

Figure 6. Bar chart with the percentages of all land-use types in each continent.

\subsection{Relative Importance of the Spatial Predictor Variables}

Table 3 presents the calculated relative contributions of each influential variable in the modelling process for environmental suitability. The most significant factor is precipitation, accounting for $62.85 \%$ (95\%CI $62.51-63.20 \%$ ) of the variation, followed by land cover, which contributes $17.38 \%(95 \%$ CI $17.10-17.66 \%)$ to the total. The sum of the remaining seven factors, listed in descending order, accounts for only less than $20 \%$ of the total, which are soil water content $(6.26 \%(95 \%$ CI $5.93-6.59 \%))$, minimum annual temperature (4.52\% (95\%CI 4.22-4.82\%)), mean solar radiation (4.18\% (95\%CI 3.97-4.38\%)), maximum annual temperature $(2.83 \%(95 \% \mathrm{CI} 2.58-3.08 \%))$, soil class $(0.99 \%(95 \% \mathrm{CI} 0.92-1.06 \%))$, and soil depth $(0.01 \%(95 \% \mathrm{CI} 0-0.01 \%))$. 
Table 3. Relative contribution of each spatial predictor variables.

\begin{tabular}{cccc}
\hline Environmental Conditions & Covariates & Mean (\%) & 95\%CI \\
\hline \multirow{2}{*}{ Climate } & $\begin{array}{c}\text { Annual cumulative } \\
\text { precipitation } \\
\text { Minimum } \\
\text { temperature }\end{array}$ & 62.85 & $62.51-63.20$ \\
& $\begin{array}{c}\text { Mean solar radiation } \\
\text { Maximum }\end{array}$ & 4.52 & $4.22-4.82$ \\
& temperature & 2.83 & $3.97-4.38$ \\
& Soil water content & 6.26 & $2.58-3.08$ \\
\hline \multirow{2}{*}{ Soil } & Soil class & 0.99 & $5.93-6.59$ \\
& Soil depth & 0.01 & $0.92-1.06$ \\
& Slope & 0.98 & $0.00-0.01$ \\
\hline Topography & Land cover & 17.38 & $17.10-17.66$ \\
\hline Land use & & &
\end{tabular}

Figure 7 depicts the marginal effect curves of the major spatial predictors. There is a highly positive association between the probability of suitable land and precipitation before the rainfall hits $1000 \mathrm{~mm}$, after which the growth of the probability with precipitation becomes considerably slow. The profiles of soil water content, minimum annual temperature, and mean solar radiation exhibit positive relationships between the possibility of potentially ideal land for giant silvergrass and these three variables. Maximum annual precipitation, on the other hand, is observed to have a negative association with the probability.
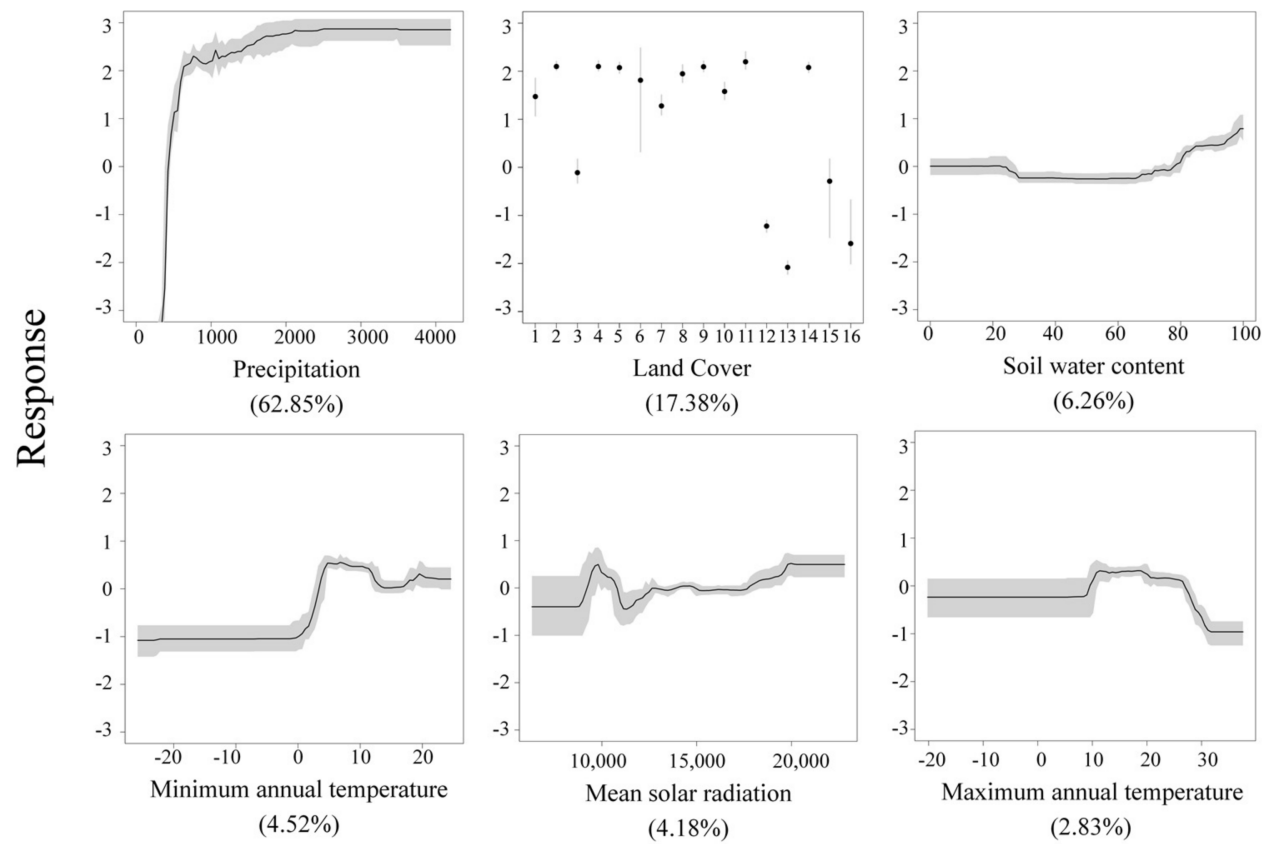

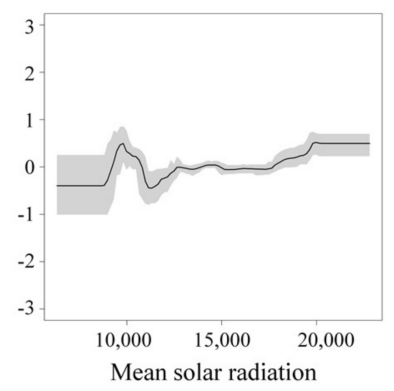

$(4.18 \%)$

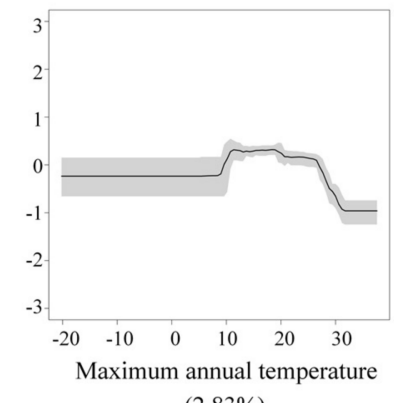

$(2.83 \%)$

Figure 7. Marginal effect curves of major spatial predictors in the ensemble BRT model fitted to the full data set. The land-use classes that the values in the graph stand for are listed as follows: (1) Evergreen Needleleaf Forests, (2) Evergreen Broadleaf Forests, (3) Deciduous Needleleaf Forests, (4) Deciduous Broadleaf Forests, (5) Mixed Forests, (6) Closed Shrublands, (7) Open Shrublands, (8) Woody Savannas, (9) Savannas, (10) Grasslands, (11) Permanent Wetlands, (12) Croplands, (13) Urban and Built-up Lands, (14) Cropland/Natural Vegetation Mosaics, (15) Permanent Snow and Ice, (16) Barren. 


\section{Discussion}

As a promising energy plant, the current research on giant silvergrass mainly focuses on assessing biomass potential, and the economic and environmental benefits based on the statistical data [36,42-45]. There are only a few studies working on the potential land resources for growing giant silvergrass. Xue et al.'s estimation through multi-factor analysis shows that 172 million hectares of marginal land are available for producing giant silvergrass [15], which is larger than our results of 129.64 million hectares. This is because the resulting values obtained from the multi-factor analysis are 0 and 1, representing unsuitability or suitability for planting giant silvergrass, respectively, and therefore, they fail to reflect the spatial variability of land resources suitable for giant silvergrass $[46,47]$. In contrast, the output values from the machine learning method in our study ranging from 0 to 1 could reflect more refined information. Xue et al.'s results provide a reference for this study, and we have made quite a lot of improvements to their research. For example, in our study, areas identified with high environmental suitability for planting (value $>0.5$ ) and that can be prioritized to be exploited have higher resulting values than those with low environmental suitability when other restrictive conditions are met. In addition, the growth of energy plants is complexly influenced by the interaction of various environmental factors, of which the contributions to energy plants' growth were equally considered. In this study, we combined the occurrence records of giant silvergrass with the corresponding environmental factors to simulate the potential land resources through the BRT model, and we, therefore, obtained the contribution of different elements to the growth of giant silvergrass and the response curves exhibiting the relationships between the growth of plants and these elements. This is very helpful for the scientific planning of giant silvergrass-based bioenergy development.

The global spatial distribution of marginal land suitable for giant silvergrass in this study provides a macroscopic map from the perspective of environmental suitability. In practice, bioenergy production has complex interactions with other social and environmental systems [48]. Bioenergy development requires us to consider marginal land resources, the process of biomass energy production, ecological protection policy, energy conservation, and emission reduction benefits, and so on. Countries need to determine their developable potential land resources based on their actual situation. For example, in China, ecological civilization and protection take precedence over marginal land development. Examples are the implemented national nature reserve policy and ecological protection red line policy [19]. Consequently, the actual amount of marginal land that can be exploited in China will be less than the results of this study. For another example, the United States and Brazil, having a large amount of marginal land, are the two leading producers of biofuels, accounting for around $80 \%$ of global production [11]. Therefore, the United States and Brazil have the greatest potential to exploit marginal land resources. In general, this paper provides a map of the potential global distribution of marginal land suitable for giant silvergrass from the perspective of environmental suitability. However, with respect to the notable differences between these regions, the developing conditions for marginal land in each region should be further constrained according to local policies.

\section{Conclusions}

This study used a machine learning method with the specifically selected environmental factors and a boosting regression tree to identify the potential marginal land suitable for giant silvergrass. The results indicate that 3068.25 million hectares of land resources worldwide are suitable for giant silvergrass cultivation, of which the main land-use types are woody savannas and savannas. The marginal land suitable for giant silvergrass is mainly distributed in Africa (902.05 million hectares), followed by Asia (620.32 million hectares), South America (547.60 million hectares), and North America (529.26 million hectares). Among all the countries possessing marginal land resources for giant silvergrass, Russia and Brazil own the most resources, which are the only two countries with more than 300 million hectares of land resources, with 373.35 and 332.37 million hectares, re- 
spectively. From the perspective of environmental suitability, climate conditions had the greatest influence on growing giant silvergrass, especially precipitation, which contributed $62.85 \%(95 \%$ CI $62.51-63.20 \%)$ to the spatial distribution of giant silvergrass.

The potential land resources of energy plant cultivation are the basis for the large-scale development of bioenergy. This study provides more granular data for the development of political procurement. Our results identify land resource development from the perspective of environmental suitability prior to deciding the locations of plantations suiting specific requirements and constraints of different countries. Moreover, this study found that precipitation has the biggest impact on giant silvergrass compared to other elements. Therefore, in terms of management, it is possible to optimize the growth conditions of giant silvergrass through technical means to obtain higher yields.

In the present study, the variables used in the BRT model might be incomprehensive. We are aware that the development of energy plants is also affected by other environmental constraints, such as acid rain, accumulated temperature, and protected area distribution data $[49,50]$, which are limited by data acquisition and were, therefore, not included in this article. In future research, more environmental elements could be included to obtain the finer potential spatial distribution of land resources suitable for energy plants. In addition, the potential land resource distribution of energy plants varies with climate change. Hence, future climate pattern data can be taken into consideration to simulate the potential land resources distribution of energy plants. In general, this research can assist governments in advancing future biomass development policies and plans.

Author Contributions: Conceptualization, D.J. and M.H.; methodology, F.D. and M.H.; software, F.D.; validation, F.D. and S.C.; formal analysis, F.D.; data curation, S.C.; writing-original draft preparation, M.H., S.C. and Y.Q.; writing-review and editing, M.H., S.C. and Y.Q.; visualization, Y.Q.; supervision, D.J. All authors have read and agreed to the published version of the manuscript.

Funding: This research was funded by the Ministry of Science and Technology of China, grant number 2020YFC1807404.

Acknowledgments: We thank Tian Ma and Xiaolan Xie for providing valuable suggestions.

Conflicts of Interest: The authors declare no conflict of interest.

\section{References}

1. Liu, X.S.; Vedlitz, A.; Alston, L. Regional news portrayals of global warming and climate change. Environ. Sci. Policy 2008, 11, 379-393. [CrossRef]

2. Lennard, C.J.; Nikulin, G.; Dosio, A.; Moufouma-Okia, W. On the need for regional climate information over Africa under varying levels of global warming. Environ. Res. Lett. 2018, 13, 040601. [CrossRef]

3. U.C.C.C.U. COP 26 Goals. 2021. Available online: https:/ / ukcop26.org/cop26-goals / (accessed on 1 September 2020).

4. Wyns, A.; Beagley, J. COP26 and beyond: Long-term climate strategies are key to safeguard health and equity. Lancet Planet. Health 2021, 5, E752-E754. [CrossRef]

5. Jacobs, M. Reflections on COP26: International Diplomacy, Global Justice and the Greening of Capitalism. Political Q. 2021. [CrossRef]

6. Rodriguez-Alloza, A.M.; Heihsel, M.; Fry, J.; Gallego, J.; Geschke, A.; Wood, R. and Lenzen, M. Consequences of long-term infrastructure decisions?the case of self-healing roads and their $\mathrm{CO}_{2}$ emissions. Environ. Res. Lett. 2019, 14, 114040. [CrossRef]

7. Koelbl, B.S.; van den Broek, M.A.; van Ruijven, B.J.; Faaij, A.P.C.; van Vuuren, D.P. Uncertainty in the deployment of Carbon Capture and Storage (CCS): A sensitivity analysis to techno-economic parameter uncertainty. Int. J. Greenh. Gas Control 2014, 27, 81-102. [CrossRef]

8. López-Peña, Á.; Pérez-Arriaga, I.; Linares, P. Renewables vs. energy efficiency: The cost of carbon emissions reduction in Spain. Energy Policy 2012, 50, 659-668. [CrossRef]

9. Ramachandra, T.V.; Joshi, N.V.; Subramanian, D.K. Present and prospective role of bioenergy in regional energy system. Renew. Sustain. Energy Rev. 2000, 2000, 56. [CrossRef]

10. Cornelissen, S.; Koper, M.; Deng, Y.Y. The role of bioenergy in a fully sustainable global energy system. Biomass Bioenergy 2012, 41, 21-33. [CrossRef]

11. REN21 (2021) Renewables 2021 Global Status Report; REN21 Secretariat: Paris, France, 2021.

12. Dubis, B.; Jankowski, K.J.; Załuski, D.; Bórawski, P.; Szempliński, W. Biomass production and energy balance of Miscanthus over a period of 11 years: A case study in a large-scale farm in Poland. GCB Bioenergy 2019, 11, 1187-1201. [CrossRef] 
13. Xue, S.; Lewandowski, I.; Wang, X.; Yi, Z. Assessment of the production potentials of Miscanthus on marginal land in China. Renew. Sustain. Energy Rev. 2016, 54, 932-943. [CrossRef]

14. Ma, L.Y.; Rocha, F.I.; Lee, J.; Choi, J.; Tejera, M.; Sooksa-Nguan, T.; Boersma, N.; VanLoocke, A.; Heaton, E.; Howe, A. The Impact of Stand Age and Fertilization on the Soil Microbiome of Miscanthus $\times$ giganteus. Phytobiomes J. 2021, 5, 51-59. [CrossRef]

15. Turner, W.; Greetham, D.; Mos, M.; Squance, M.; Kam, J.; Du, C.Y. Exploring the Bioethanol Production Potential of Miscanthus Cultivars. Appl. Sci. 2021, 11, 9949. [CrossRef]

16. Shortall, O.K. “Marginal land” for energy crops: Exploring definitions and embedded assumptions. Energy Policy 2013, 62, 19-27. [CrossRef]

17. Khanna, M.; Chen, L.; Basso, B.; Cai, X.; Field, J.L.; Guan, K.; Jiang, C.; Lark, T.J.; Richard, T.L.; Spawn-Lee, S.A.; et al. Redefining marginal land for bioenergy crop production. GCB Bioenergy 2021, 13, 1590-1609. [CrossRef]

18. Zhuang, D.; Jiang, D.; Liu, L.; Huang, Y. Assessment of bioenergy potential on marginal land in China. Renew. Sustain. Energy Rev. 2011, 15, 1050-1056. [CrossRef]

19. Jiang, D.; Hao, M.; Fu, J.; Huang, Y.; Liu, K. Evaluating the bioenergy potential of cassava on marginal land using a biogeochemical process model in GuangXi, China. J. Appl. Remote Sens. 2015, 9, 1-11. [CrossRef]

20. Jiang, D.; Hao, M.; Fu, J.; Liu, K.; Yan, X. Potential bioethanol production from sweet sorghum on marginal land in China J. Clean. Prod. 2019, 220, 225-234. [CrossRef]

21. Lu, L.; Jiang, D.; Zhuang, D.; Huang, Y. Evaluating the Marginal Land Resources Suitable for Developing Pistacia chinensis-Based Biodiesel in China. Energies 2012, 5, 2165-2177. [CrossRef]

22. Liu, L.; Zhuang, D.; Jiang, D.; Fu, J. Assessment of the biomass energy potentials and environmental benefits of Jatropha curcas L. in Southwest China. Biomass Bioenergy 2013, 56, 342-350. [CrossRef]

23. Liu, T.; Huffman, T.; Kulshreshtha, S.; McConkey, B.; Du, Y.; Green, M.; Liu, J.; Shang, J.; Geng, X. Bioenergy production on marginal land in Canada: Potential, economic feasibility, and greenhouse gas emissions impacts. Appl. Energy 2017, 205, 477-485. [CrossRef]

24. Karpatne, A.; Jiang, Z.; Vatsavai, R.R.; Shekhar, S.; Kumar, V. Monitoring Land-Cover Changes: A Machine-Learning Perspective IEEE Geosci. Remote Sens. Mag. 2016, 4, 14. [CrossRef]

25. Ojha, S.K.; Challa, K.; Vemuri, M.K.; Yarlagadda, N.S.V.; Kumar, B.L.N.P. Land Use Prediction on Satillite images using Deep Neural Nets. In Proceedings of the International Conference on Intelligent Computing and Control Systems, Madurai, India, 25-27 May 2019; Anna. Univ., Vaigai Coll. Engn.: Madurai, India, 2009; pp. 999-1003.

26. Yang, P.; Zhao, Q.; Cai, X. Machine learning based estimation of land productivity in the contiguous US using biophysical predictors. Environ. Res. Lett. 2020, 15, 1-32. [CrossRef]

27. Jiang, D.; Ma, T.; Ding, F.; Fu, J.; Hao, M.; Wang, Q.; Chen, S. Mapping Global Environmental Suitability for Sorghum bicolor (L.) Moench. Energies 2019, 12, 1928. [CrossRef]

28. Fan, P.; Hao, M.; Ding, F.; Jiang, D.; Dong, D. Quantifying Global Potential Marginal Land Resources for Switchgrass. Energies 2020, 13, 6197. [CrossRef]

29. Jiang, D.; Wang, Q.; Ding, F.; Fu, J.; Hao, M. Potential marginal land resources of cassava worldwide: A data-driven analysis Renew. Sustain. Energy Rev. 2019, 104, 167-173. [CrossRef]

30. Ben Fradj, N.; Rozakis, S.; Borzęcka, M.; Matyka, M. Miscanthus in the European bio-economy: A network analysis. Ind. Crops Prod. 2020, 148, 1-30. [CrossRef]

31. Fick, S.E.; Hijmans, R.J. WorldClim 2: New 1km spatial resolution climate surfaces for global land areas. Int. J. Climatol. 2017, 37, 4302-4315. [CrossRef]

32. World Soil Information. Available online: http://www.isric.org (accessed on 25 December 2021).

33. CGIAR Consortium for Spatial Information. Available online: http://srtm.csi.cgiar.org (accessed on 25 December 2021).

34. Jarvis, A.; Guevara, E.; Reuter, H.I.; Nelson, A.D. Hole-Filled SRTM for the Globe: Version 4, International Centre for Tropical Agriculture (CIAT). Available online: https:/ / cgiarcsi.community/data/srtm-90m-digitalelevation-database-v4-1/ (accessed on 25 December 2021).

35. NASA's Earth Observatory Group. Available online: https://lpdaac.usgs.gov/ (accessed on 25 December 2021).

36. Friedl, M.A.; Sulla-Menashe, D.; Tan, B.; Schneider, A.; Ramankutty, N.; Sibley, A.; Huang, X. MODIS Collection 5 global land cover: Algorithm refinements and characterization of new datasets. Remote Sens. Environ. 2010, 114, 168-182. [CrossRef]

37. Kim, J.-C.; Lee, S.; Jung, H.-S.; Lee, S. Landslide susceptibility mapping using random forest and boosted tree models in Pyeong-Chang, Korea. Geocarto Int. 2017, 33, 16. [CrossRef]

38. Bosisio, A.; Moncecchi, M.; Morotti, A.; Merlo, M. Machine Learning and GIS Approach for Electrical Load Assessment to Increase Distribution Networks Resilience. Energies 2021, 14, 4133. [CrossRef]

39. Li, C.; Liu, M.; Hu, Y.; Xu, Y.; Sun, F. Driving forces analysis of urban expansion based on boosted regression trees and Logistic regression. Acta Ecol. Sin. 2014, 34, 11.

40. Singh, U.; Rizwan, M.; Alaraj, M.; Alsaidan, I. A Machine Learning-Based Gradient Boosting Regression Approach for Wind Power Production Forecasting: A Step towards Smart Grid Environments. Energies 2021, 14, 5196. [CrossRef]

41. Gao, X.; Qi, C.; Xue, G.; Song, J.; Zhang, Y.; Yu, S.-a. Forecasting the Heat Load of Residential Buildings with Heat Metering Based on CEEMDAN-SVR. Energies 2020, 13, 6079. [CrossRef] 
42. Olba-Zięty, E.; Stolarski, M.J.; Krzyżaniak, M. Economic Evaluation of the Production of Perennial Crops for Energy Purposes-A Review. Energies 2021, 14, 7147. [CrossRef]

43. Jach-Nocoń, M.; Pełka, G.; Luboń, W.; Mirowski, T.; Nocoń, A.; Pachytel, P. An Assessment of the Efficiency and Emissions of a Pellet Boiler Combusting Multiple Pellet Types. Energies 2021, 14, 4465. [CrossRef]

44. Mangold, A.; Lewandowski, I.; Hartung, J.; Kiesel, A. Miscanthus for biogas production: Influence of harvest date and ensiling on digestibility and methane hectare yield. GCB Bioenergy 2019, 11, 50-62. [CrossRef]

45. Clifton-Brown, J.C.; Breuer, J.; Jones, M.B. Carbon mitigation by the energy crop, Miscanthus. Glob. Chang. Biol. 2007, 13, 2296-2307. [CrossRef]

46. Kang, S.; Post, W.; Wang, D.; Nichols, J.; Bandaru, V.; West, T. Hierarchical marginal land assessment for land use planning. Land Use Policy 2013, 30, 106-113. [CrossRef]

47. Jiang, W.; Jacobson, M.G.; Langholtz, M.H. A sustainability framework for assessing studies about marginal lands for planting perennial energy crops. Biofuels Bioprod. Biorefining 2019, 13, 228-240. [CrossRef]

48. Møller, A.B.; Mulder, V.L.; Heuvelink, G.B.M.; Jacobsen, N.M.; Greve, M.H. Can We Use Machine Learning for Agricultural Land Suitability Assessment? Agronomy 2021, 11, 703. [CrossRef]

49. Fu, J.; Dong, J.; Huang, Y.; Zhuang, D.; Wei, J. Evaluating the marginal land resources suitable for developing bioenergy in Asia. Adv. Meteorol. 2014, 2014, 238945. [CrossRef]

50. Odiyi, B.O.; Bamidele, J.J.F. Effects of Simulated Acid Rain on Growth and Yield of Cassava Manihot esculenta (Crantz). J. Agric. Sci. 2013, 6, 96-101. [CrossRef] 